\title{
Residential Control for Spotted Lanternfly (SLF) in Virginia
}

Andy Dechaine, Eric Day, and Douglas Pfeiffer, Entomology, Virginia Tech

Mark Sutphin, Extension Agent, Virginia Cooperative Extension

Introduction: Spotted Lanternfly (SLF) has quickly established itself as an agricultural pest, feeding mostly on grapes and fruit trees, but is also known to feed on many species of hardwoods. As a result, SLF has become a large residential pest where it is established.

Damage: When SLF are immature, nymphs tend to feed on smaller, new growth sections of trees and vines (Figure 1). Young trees with heavy infestations show symptoms of flagging, wilting and branch death (Figure 1). As adults, SLF will feed on any part of the tree and can cause black weeping wounds along the trunk. As SLF feed, they exude a waste product called honeydew (Figure 2). Honeydew is high in sugar content and becomes sticky as it coats a surface. Continuous deposits of honeydew on the ground, surrounding vegetation, or other surfaces, such as a patio, will eventually lead to the growth of sooty mold (Figure 2).

Hosts: The SLF has been reported to feed on as many as 70 different host species. These include: boxelder, red maple, silver maple, sugar maple, smooth sumac, hackberry, black locust, honey locust, black walnut, English Walnut, ash, elm, oak, sycamore, southern magnolia, sassafras, Korean evodia (bee-bee tree), mimosa tree, tree of heaven, white mulberry, cherry, apple, peach and grape vines. Other plants include: bush honeysuckle, Japanese honeysuckle, poison ivy, English ivy, ornamental rose, multiflora rose, burdock, garlic mustard, Virginia creeper, and hops.

Residential Control and Management: It is expected that this insect will continue to expand its range and impact residential areas. For homeowners, SLF will generally be a nuisance pest as it feeds on trees depositing honeydew on surrounding surfaces. It is important that homeowners have the information they need to help reduce the impact and spread of this insect.

Cut and Treat: Tree of heaven (Ailanthus altissima) is an invasive tree species from the SLF's native range and is known to be a preferred host species for all life stages. Homeowners can identify and remove this tree species. Tree of heaven near a house should be cut and treated with an herbicide to prevent resprouting. Multiple applications may be necessary to completely kill the tree. This action will result in decreased honeydew deposition and sooty mold development on the home, patio, etc. If you are unsure if you have tree of heaven or the tree is large, contact a tree care service or county extension personnel for advice.
Insecticide: There are several insecticides available to kill SLF in one of two ways. Contact insecticides will kill SLF when it is sprayed directly onto the insect, or when the insect walks over a surface that contains insecticide residue. Contact insecticides should be applied to tree surfaces where SLF are found feeding and walking. Limit sprays to trees when and where SLF are actively found. SLF's occur on plants from May-October. Treat starting in May and repeat as needed. Imidacloprid, carbaryl, pyrethrin, or bifenthrin are labeled for control in Virginia for spotted lanternfly on trees and shrubs. Check the insecticide label, spotted lanternfly does not need to be on the label, but the plant does. Make sure to use products labeled for trees and shrubs when treating back yard plantings or labeled for fruit or grapes when using it on those plants.

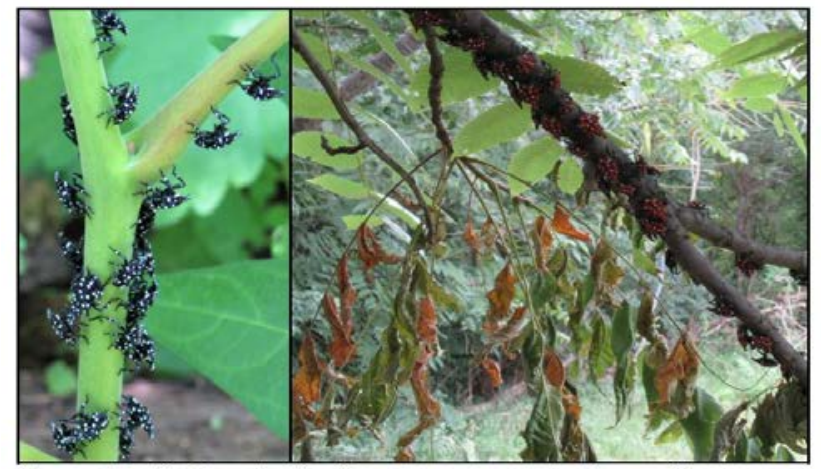

Figure 1 Left: Nymphs feeding on new growth of tree of heaven. Right: Fourth instar nymphs feeding on black walnut. Note wilting of leaves. Photos by Andrew Dechaine

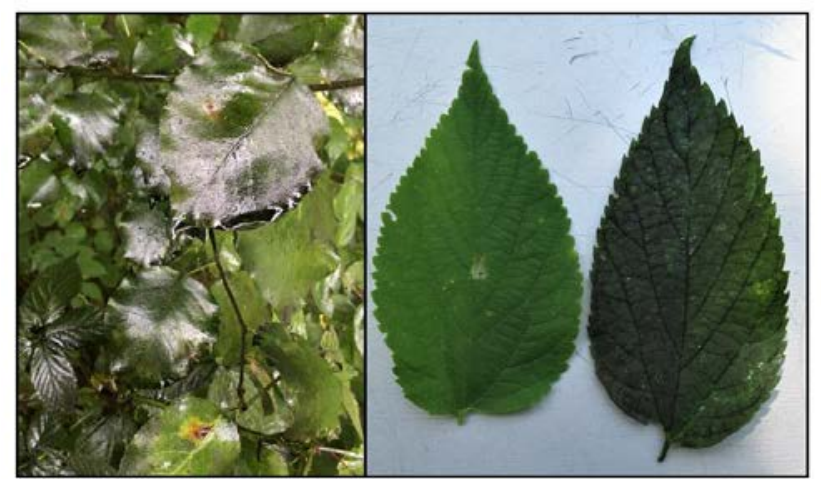

Figure 2 Left: Leaves have a glossy or wet appearance as a result of honeydew. Photo by Mark Sutphin Right: Hackberry leaves with and without sooty mold. Photo by Andrew Dechaine 
Systemic insecticides are taken up by the tree and the insect receives a dose when it feeds on the liquids of the tree. These insecticides are applied as a soil drench around the base of the tree, a bark application, or injected into the tree near the base. It is recommended that a tree injection is used as this method will limit human exposure to the insecticide. However, a tree injection requires special equipment and a professional will need to be employed.

It is important to consider non-target insects when deciding to apply an insecticide. Application should be made after the tree is done flowering for the season. This will limit unwanted negative impact to pollinators and other beneficial insects such as honey bees. Contact your local extension personnel or professional tree service for recommendations.

Biological Controls: There are no effective natural enemies at this time.

Slow the Spread: Keep a keen eye out for egg masses. It is thought that the main way this insect is going to spread large distances is through unintentional human transport. As stated, SLF will lay their eggs on many surfaces other than trees. This could mean firewood, a backyard grill, garden equipment and debris, patio furniture, waste bins, hunting stands and blinds, pallets, and even a car or truck. If you live in or visit an area that is infested with SLF be sure to inspect your vehicle and objects stored outside to prevent unintentional spread. If egg masses are found, scrape them off the surface and destroy them. A stick, credit card, screwdriver, putty or pocket knife, etc. can be used as a scraper. Eggs can be dropped into rubbing alcohol, hand sanitizer, burned, or simply crushed with your shoe.

Homeowners are encouraged to inspect their vehicles and cargo for any life stage of SLF before leaving Winchester or Frederick County.

Virginia Distribution: The Spotted Lanternfly (SLF) is a newly introduced insect species to the United States that was first discovered in Berks County, Pennsylvania in 2014. This invasive planthopper is native to China and since its introduction has spread to 13 other counties in PA and can also been found in New Jersey, Delaware, and Virginia. As of July 2019, the current distribution of SLF in Virginia is restricted to the city of Winchester and nearby Frederick County.

Biology and Identification: The spotted lanternfly can be described as going through three life stages with a single generation per year overwintering as an egg. Eggs masses are laid in the fall and can be found on many different smooth surfaces but generally on trees with smooth bark (Figure 3).
Egg masses contain 30-50 eggs that are typically covered by a brownish waxy layer and are 1-1.5 inches long and 0.5-0.75 inches wide. Eggs begin to hatch in late April and continue through May. Once eggs have hatched, SLF goes through four nymphal stages referred to as instars. First, second, and third instar nymphs get progressively larger and are black with white spots on the body and legs (Figure 3). Fourth instar nymphs begin to emerge in late June and can be identified by their distinct red color with black and white spots (Figure 3). Adult SLF emerge sometime in July and are about one inch long and a half inch wide (Figure 3). Adults begin to lay eggs in September and persist through November until they can no longer survive winter temperatures. Lycorma delicatula (White) (Hemiptera: Fulgoridae).

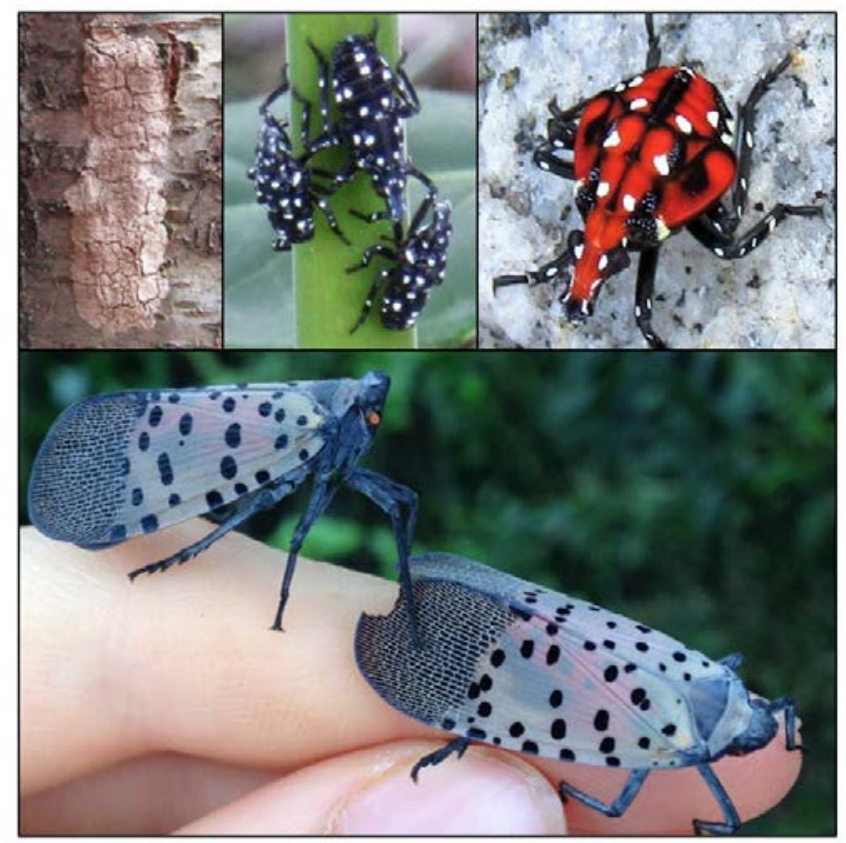

Figure 3 Top left: SLF egg mass. Top middle: First through third instar nymphs. Top right: Fourth instar nymph. Bottom: Adult SLF. Photos by Andrew Dechaine

\section{Additional Information and Reporting Suspected SLF:}

For information on Spotted Lanternfly, see: ext.vt.edu/spotted-lanternfly.

To report suspected SLF go to: https://ask.extension.org/groups/1981/ask

In addition, you may contact your local Virginia Cooperative Extension office. 